\title{
Regulating the pore structure and oxygen vacancies of cobaltosic oxide hollow dodecahedra for an enhanced oxygen evolution reaction
}

\author{
Yao Xiao ${ }^{1,2}$, Yibo Wang ${ }^{1,3}$, Meiling Xiao', Changpeng Liu', Shuai Hou (1)', Junjie Ge $\mathbb{1}^{1}$ and Wei Xing (1)
}

\begin{abstract}
Engineering an electrocatalytic anode material to boost reaction kinetics is highly desirable for the anodic oxygen evolution reaction (OER), which is the major obstacle for high efficiency water electrolysis. Here, we present a novel kind of $\mathrm{Zn}$-doped $\mathrm{CO}_{3} \mathrm{O}_{4}$ hollow dodecahedral electrocatalyst. Abundant oxygen vacancy defects are introduced due to the incorporation of $\mathrm{Zn}^{2+}$, which is beneficial for $\mathrm{OH}^{-}$adsorption and the charge transfer reaction during the OER process. Moreover, the increase in surface area caused by the advanced structure of the hollow porous dodecahedra facilitates mass transport by increasing the surface area. The novel strategy proposed in this study provides an efficient way to design high-performance electrocatalysts for water electrolysis.
\end{abstract}

\section{Introduction}

With an increasing global energy demand and an increasing concern about environmental pollution from fossil fuels, an increasing amount of research on energy conversion from sustainable energy sources has been stimulated ${ }^{1}$. Renewable alternatives such as wind and solar energies are promising future technologies. However, they are intermittent in nature, and the storage of the generated energy is difficult. The electrochemical water splitting technique provides an ideal solution for this issue, where electricity generated from renewable energies can be stored in terms of chemical energy, i.e., in $\mathrm{H}-\mathrm{H}$ and $\mathrm{O}-\mathrm{O}$ bonds. The subsequent recombination of hydrogen and oxygen can provide clean and stable electrical energy in an on-demand manner; additionally, the only byproduct is water ${ }^{2}$. However, the efficiency of

\footnotetext{
Correspondence: Shuai Hou (houshuai@ciac.ac.cn) or Junjie Ge (gejj@ciac.ac.cn) or Wei Xing (xingwei@ciac.ac.cn)

${ }^{1}$ State Key Laboratory of Electroanalytical Chemistry, Jilin Province Key Laboratory of Low Carbon Chemical Power, Changchun Institute of Applied Chemistry

Chinese Academy of Sciences, 5625 Renmin Street, Changchun 130022, P.R. China ${ }^{2}$ College of Materials Science and Engineering, Qingdao University of Science and Technology, Qingdao 266042, P.R. China

Full list of author information is available at the end of the article

These authors contributed equally: Yao Xiao, Yibo Wang
}

hydrogen fuel generation from water splitting is severely limited by the sluggish kinetics of oxygen evolution ${ }^{3}$. Therefore, an efficient electrocatalyst for the oxygen evolution reaction (OER) is needed to provide a high current density at a low overpotential and improve the energy conversion efficiency. Although iridium oxide $\left(\mathrm{IrO}_{2}\right)$ and ruthenium oxide $\left(\mathrm{RuO}_{2}\right)$ are widely recognized as the most active electrocatalysts for the $\mathrm{OER}^{4}$, their scarcity and high cost have limited their wide application. Therefore, it is urgent to develop cheap and efficient electrocatalysts for the OER process.

Recently, a range of low-cost metal electrocatalysts have been reported to exhibit outstanding catalytic performances for the OER. Among them, transition metal oxides, especially nickel and cobaltosic oxides, have emerged as promising alternates for $\mathrm{IrO}_{2}$ and $\mathrm{RuO}_{2}$ because of their abundance, stability and rich variability of valence states $^{5-9}$. The performances of $\mathrm{Co}_{3} \mathrm{O}_{4}$ catalysts for the OER are generally affected by their morphology and composition. First, it is well known that the performance of catalysts strongly depends on structural parameters, including the particle size, surface area and morphology $^{10,11}$. A series of templates, such as silica ${ }^{12}$, carbon ${ }^{13}$ and monodispersed polymer ${ }^{14}$, can be used to modify the 
particle structure of catalysts. However, traditional template-assisted approaches are complicated because they require further postprocessing to remove the templates. Metal organic frameworks (MOFs) can be used as sacrificial templates to overcome the shortcomings mentioned above with an increased surface area and advanced pore structure. For example, Huang's group synthesized highly symmetric $\mathrm{Co}_{3} \mathrm{O}_{4}$ hollow dodecahedra by a thermal treatment with ZIF-67 as a template ${ }^{15}$. Ohet al. prepared multiball-in-ball hybrid metal oxides with spherical MOFs as sacrificial templates by taking advantage of their unique reactivity and thermal behavior ${ }^{16}$. Second, the catalytic activities of $\mathrm{Co}_{3} \mathrm{O}_{4}$ for the OER can be improved by doping ${ }^{17-19}$. For instance, a high OER performance has been achieved by using novel hierarchical $\mathrm{Zn}_{\mathrm{x}} \mathrm{Co}_{3-\mathrm{x}} \mathrm{O}_{4}$ nanostructures constructed with small secondary nanoneedles grown on primary rhombus-shaped pillar arrays $^{17}$. Alexander Eychmüller et al. developed a class of nickel cobalt oxide hollow nanosponges that exhibited higher catalytic activity toward the OER compared with its undoped $\mathrm{Co}_{3} \mathrm{O}_{4}$ counterpart ${ }^{20}$. However, the improved performances of doped $\mathrm{Co}_{3} \mathrm{O}_{4}$ catalysts are usually ascribed to the increase in the number of active sites caused by the valence state transfer of cobalt, and there is no in-depth and comprehensive elaboration about the effect of doping.

The OER is a liquid-to-gas electrochemical conversion that requires the multiscale control of catalysts to make each involved reaction step proceed smoothly. These steps include sufficient mass transport, abundant active sites and sufficient catalytic capability. Herein, we present a novel $\mathrm{Zn}$-doped $\mathrm{Co}_{3} \mathrm{O}_{4}$ hollow dodecahedral electrocatalyst with a high catalytic efficiency for the OER using MOFs with different $\mathrm{Co} / \mathrm{Zn}$ ratios as templates. At the macroscale, its unique porous hollow structure increases catalytic activity by facilitating mass transport and exposing abundant active sites. At the nanoscale, some of the $\mathrm{Zn}$ in the precursor was trapped in the lattice of $\mathrm{Co}_{3} \mathrm{O}_{4}$, replacing both $\mathrm{Co}^{2+}$ at tetrahedral sites and $\mathrm{Co}^{3+}$ at octahedral sites. Owing to the incorporation of $\mathrm{Zn}^{2+}$, abundant oxygen vacancy defects are introduced. The oxygen vacancies are beneficial for $\mathrm{OH}^{-}$adsorption ${ }^{21}$ and electronic transfers ${ }^{22}$, thereby achieving the needed multiscale modulation to synergistically boost the OER electrochemical process.

\section{Experimental section}

\section{Synthesis of $\mathrm{Zn}_{\mathrm{x}} \mathrm{Co}-\mathrm{MOF}$}

All chemicals were analytical grade, purchased from Aladdin Chemistry Corporation (Shanghai, China) and used without further purification.

In a typical synthesis ${ }^{15}, \mathrm{Zn}\left(\mathrm{NO}_{3}\right)_{2} \cdot 6 \mathrm{H}_{2} \mathrm{O}$ and $\mathrm{Co}$ $\left(\mathrm{NO}_{3}\right)_{2} \cdot 6 \mathrm{H}_{2} \mathrm{O}$ with different molar ratios of $\mathrm{Zn}$ :Co $(0,1: 1$, $1: 3$, and 1:5), were mixed in $100 \mathrm{~mL}$ of methanol at room temperature. Then, $3.056 \mathrm{~g}$ of 2-methylimidazolate was dissolved in another $100 \mathrm{~mL}$ of methanol. The above two solutions were then mixed under vigorous stirring at room temperature for $24 \mathrm{~h}$. The precipitates were collected by centrifugation and washed several times with methanol and then dried at $80^{\circ} \mathrm{C}$ for $12 \mathrm{~h}$.

\section{Synthesis of the $\mathrm{Co}_{3} \mathrm{O}_{4}$ hollow dodecahedra}

The Co-MOF powder was loaded in a quartz boat and placed in a tube furnace. Then, Co-MOF was heated to $350^{\circ} \mathrm{C}$ at a rate of $5^{\circ} \mathrm{C} \mathrm{min}^{-1}$ and maintained for $30 \mathrm{~min}$ in flowing nitrogen. After that, the $\mathrm{N}_{2}$ was switched to air, and the furnace was maintained at $350^{\circ} \mathrm{C}$ for another $30 \mathrm{~min}$ in air.

\section{Synthesis of $\mathrm{Zn}$-doped $\mathrm{Co}_{3} \mathrm{O}_{4}$ hollow dodecahedra}

$\mathrm{Zn}$-doped $\mathrm{Co}_{3} \mathrm{O}_{4}$ hollow dodecahedra were synthesized by the same procedure as 2.2 except that the precursor was $\mathrm{Zn}_{\mathrm{x}} \mathrm{Co}-\mathrm{MOF}$ ( $x=1: 1,1: 3$, and 1:5). The $\mathrm{Zn}$-doped $\mathrm{Co}_{3} \mathrm{O}_{4}$ hollow dodecahedra derived from $\mathrm{ZnCo-MOF}$, $\mathrm{ZnCo}_{3}-\mathrm{MOF}$ and $\mathrm{ZnCo}_{5}-\mathrm{MOF}$ were denoted as $\mathrm{Zn}$-doped $\mathrm{Co}_{3} \mathrm{O}_{4}-1$, Zn-doped $\mathrm{Co}_{3} \mathrm{O}_{4}-2$, and $\mathrm{Zn}$-doped $\mathrm{Co}_{3} \mathrm{O}_{4}-3$, respectively.

\section{Materials characterization}

X-ray diffraction (XRD) patterns of the catalysts were obtained using a Rigaku-D/MAX-PC2500 X-ray diffractometer (Japan) with $\mathrm{Cu} \mathrm{K \alpha}\left(1 \frac{1}{1} 1.5405 \AA\right)$ as a radiation source and operated at $40 \mathrm{kV}$ and $200 \mathrm{~mA}$. X-ray photoelectron spectroscopy (XPS) was recorded on a Kratos XSAM-800 spectrometer with an $\mathrm{Al} \mathrm{K} \alpha$ monochromatic source. Scanning electron microscopy (SEM) images were taken using an FEI XL30 ESEM FEG scanning electron microscope. Transmission electron microscopy (TEM) was carried out with a JEOL2010 microscope operating at $200 \mathrm{kV}$ with a nominal resolution. The porous structure of the samples was investigated using $\mathrm{N}_{2}$ adsorption at $-196^{\circ} \mathrm{C}$ using a Micromeritics ASAP 2020 instrument.

\section{Electrochemical measurements}

Electrochemical measurements were performed with a Versa STAT potentiostat/galvanostat controlled by Versa Studio software (Princeton Applied Research). A conventional three-electrode cell was used. $\mathrm{A} \mathrm{Hg} / \mathrm{HgO}$ electrode was used as the reference electrode, and Pt foil was used as the counter electrode. Potentials were transferred to a reversible hydrogen electrode (RHE) by adding $(0.098+0.059 \mathrm{pH}) \mathrm{V}$. All experiments were carried out at ambient temperature. The working electrode was prepared as follows. The catalyst ink was prepared by dispersing $5 \mathrm{mg}$ of catalyst in $950 \mathrm{~mL}$ of ethanol with $50 \mu \mathrm{L}$ of $5 \mathrm{wt} \%$ Nafion solution. Then, $5 \mu \mathrm{L}$ of the catalyst ink was loaded on a glassy carbon electrode and dried at room 
temperature. The mass loading was $0.35 \mathrm{mg} \mathrm{cm}^{-2}$. All data are presented with $95 \%$ iR compensation.

\section{Results and discussion}

$\mathrm{Zn}$-doped $\mathrm{Co}_{3} \mathrm{O}_{4}$ hollow dodecahedra were prepared by the thermal treatment of MOFs with different $\mathrm{Co} / \mathrm{Zn}$ ratios. SEM images of the synthesized MOF samples are shown in Fig. S1, in which the formation of highly uniform Co-MOF particles can be clearly observed (Fig. S1A). To further confirm the structure of Co-MOF, a single crystal from different positions of view is shown in the inset of Fig. S1A, revealing its rhombic dodecahedral structure. Figure S1B exhibits the SEM image of $\mathrm{ZnCo}_{3}-$ MOF. $\mathrm{ZnCo}_{3}-\mathrm{MOF}$ retains its dodecahedral crystal structure despite different contents of $\mathrm{Zn}$ doping. Figure 1A presents the SEM image of $\mathrm{Co}_{3} \mathrm{O}_{4}$ hollow dodecahedra derived from the thermal treatment of Co-MOF, demonstrating that the dodecahedral morphology of the Co-MOF precursor is well preserved. The rough surface of the dodecahedra indicates the polycrystalline nature of the Co-MOF, with the formation of connected nanoparticles due to the confinement of the MOF. An evident porous structure is noticed due to the removal of carbon during the thermal treatment process. $\mathrm{Zn}$-doped $\mathrm{Co}_{3} \mathrm{O}_{4}-2$ almost preserves the dodecahedral structure except for a slight collapse, as shown in Fig. 1B. The crystal structure of $\mathrm{Zn}$-doped $\mathrm{Co}_{3} \mathrm{O}_{4}-2$ can be further confirmed by TEM. As displayed in Fig. 1C, the inner part of the dodecahedra is brighter than the outer part, confirming the hollow nanostructure of the $\mathrm{Co}_{3} \mathrm{O}_{4}-2$ particles. The highresolution TEM (HRTEM) image taken of $\mathrm{Zn}$-doped $\mathrm{Co}_{3} \mathrm{O}_{4}$-2 (Fig. 1D) reveals clear lattice fringes with interplanar spacings of 0.24 and $0.28 \mathrm{~nm}$ corresponding to the (311) and (220) planes of $\mathrm{Co}_{3} \mathrm{O}_{4}$, respectively. The selective area electron diffraction (SAED) pattern (Fig. 1E) shows several bright rings consisting of discrete spots, which can be indexed to the (220), (311), and (400) planes of $\mathrm{Co}_{3} \mathrm{O}_{4}$. Figure $1 \mathrm{~F}$ demonstrates the scanning TEM (STEM) image and the corresponding EDX elemental mapping images of $\mathrm{Co}, \mathrm{Zn}$, and $\mathrm{O}$ of $\mathrm{Zn}$-doped $\mathrm{Co}_{3} \mathrm{O}_{4}-2$, revealing that $\mathrm{Co}, \mathrm{Zn}$, and $\mathrm{O}$ are uniformly distributed. The X-ray diffraction (XRD) patterns of different samples are presented in Fig. 2A. According to the standard JCPD card No. 43-1003, the diffraction peaks emerging at 19.0, $31.3,36.8,59.4$, and $65.2^{\circ}$ are related to the (111), (220), (311), (511), and (440) planes of cubic-phase $\mathrm{Co}_{3} \mathrm{O}_{4}$. For the doped samples, no additional diffraction peaks appear regardless of the variation in the $\mathrm{Co} / \mathrm{Zn}$ ratio, which indicates the isomorphous replacement of $\mathrm{Zn}^{2+}$ in the $\mathrm{Co}_{3} \mathrm{O}_{4}$ lattice ${ }^{23}$. It is noted that broadening in the diffraction peaks is observed with an increased $\mathrm{Zn}$ content in the oxides, which is ascribable to the decrease in particle size of the $\mathrm{Zn}$-doped $\mathrm{Co}_{3} \mathrm{O}_{4}$ samples ${ }^{24}$.
X-ray photoelectron spectroscopy (XPS) was performed to quantify $\mathrm{O}, \mathrm{Co}$, and $\mathrm{Zn}$ in the samples, as well as to investigate their chemical states and stoichiometry. The XPS survey spectra of $\mathrm{Zn}$-doped $\mathrm{Co}_{3} \mathrm{O}_{4}$ catalysts confirm the presence of $\mathrm{Zn}$ (Fig. S2). As presented in Fig. S3, two major peaks centered at 1044.2 and $1021.0 \mathrm{eV}$ can be attributed to $\mathrm{Zn} 2 \mathrm{p} 3 / 2$ and $2 \mathrm{p} 1 / 2$ of $\mathrm{Zn}^{2+}$, respectively ${ }^{25}$, indicating that $\mathrm{Zn}$ is successfully doped into the $\mathrm{Co}_{3} \mathrm{O}_{4}$ hollow dodecahedra. The detailed chemical states of the $\mathrm{Co}$ and $\mathrm{O}$ of the $\mathrm{Co}_{3} \mathrm{O}_{4}$ dodecahedra and $\mathrm{Zn}$-doped $\mathrm{Co}_{3} \mathrm{O}_{4}-2$ are illustrated in Fig. 2B, C. Figure 2B presents the high-resolution Co $2 \mathrm{p}$ spectra, in which the peaks located at 779.5 and $794.5 \mathrm{eV}$ are assigned to the position of $\mathrm{Co}^{3+}$ and the rest of the peaks are assigned to $\mathrm{Co}^{2+}$. The percentage of $\mathrm{Co}^{3+}$ can be determined by integrating the peaks of $\mathrm{Co}^{3+26}$, which are $75.8 \%, 71.5 \%, 69.4 \%$, and $72.3 \%$ for the $\mathrm{Co}_{3} \mathrm{O}_{4}$ dodecahedra, $\mathrm{Zn}$-doped $\mathrm{Co}_{3} \mathrm{O}_{4}-3$, $\mathrm{Zn}$-doped $\mathrm{Co}_{3} \mathrm{O}_{4}-2$ and $\mathrm{Zn}$-doped $\mathrm{Co}_{3} \mathrm{O}_{4}-1$, respectively (Fig. 2B and Table S1). Moreover, the number of surface oxygen vacancies increases due to $\mathrm{Zn}^{2+}$ doping, which can be confirmed by the O $1 \mathrm{~s}$ XPS spectra (Fig. 2C). The O1s XPS spectrum can be deconvoluted into several peaks, where the peak at $\sim 532 \mathrm{eV}$ indicates the presence of surface oxygen vacancies for $\mathrm{Co}_{3} \mathrm{O}_{4}{ }^{27,28}$. Remarkably, when the concentration of $\mathrm{Zn}^{2+}$ is increased, the percentage of oxygen vacancies reaches $34.3 \%$ for $\mathrm{Zn}$-doped $\mathrm{Co}_{3} \mathrm{O}_{4}-2$ and then decreases with further increases in the doping amount of $\mathrm{Zn}$ (Fig. 2C and Table S2). To further verify the differences in the oxygen vacancy concentrations, the electron paramagnetic resonance (EPR) spectra of different samples were investigated. The fingerprint signal at $g=2.003$ appears in the spectra of EPR, demonstrating the presence of oxygen vacancies ${ }^{29-31}$. As shown in Fig. 2D, the difference in the signal intensity infers the concentration variation of oxygen vacancies, which agrees with the XPS analysis. The highest EPR signal intensity further illustrates that $\mathrm{Zn}$-doped $\mathrm{Co}_{3} \mathrm{O}_{4}-2$ has the largest oxygen vacancy concentration among the other samples.

The isomorphous replacement of zinc to cobalt occurs easily owing to the similar outermost electronic configuration and ion radius ${ }^{32}$. Specifically, when $\mathrm{Co}^{2+}$ is substituted by $\mathrm{Zn}^{2+}$, the coordination of oxygen is independent of the doped atoms. However, it has recently been shown that oxygen vacancies on the surface can be formed by the substitution of $\mathrm{Co}^{3+}$ sites by $\mathrm{Zn}^{2+32}$, due to the conservation of charge. In our case, we observed the same phenomenon, where a low proportion of $\mathrm{Co}^{3+}$ is observed with an increase in the number of oxygen vacancies $^{33,34}$. On the basis of these experimental results and the reported literature, a mechanism is proposed, as shown in Fig. 3. With the proper doping amount, $\mathrm{Zn}^{2+}$ ions replace $\mathrm{Co}^{3+}$ at octahedral sites in the lattice of 


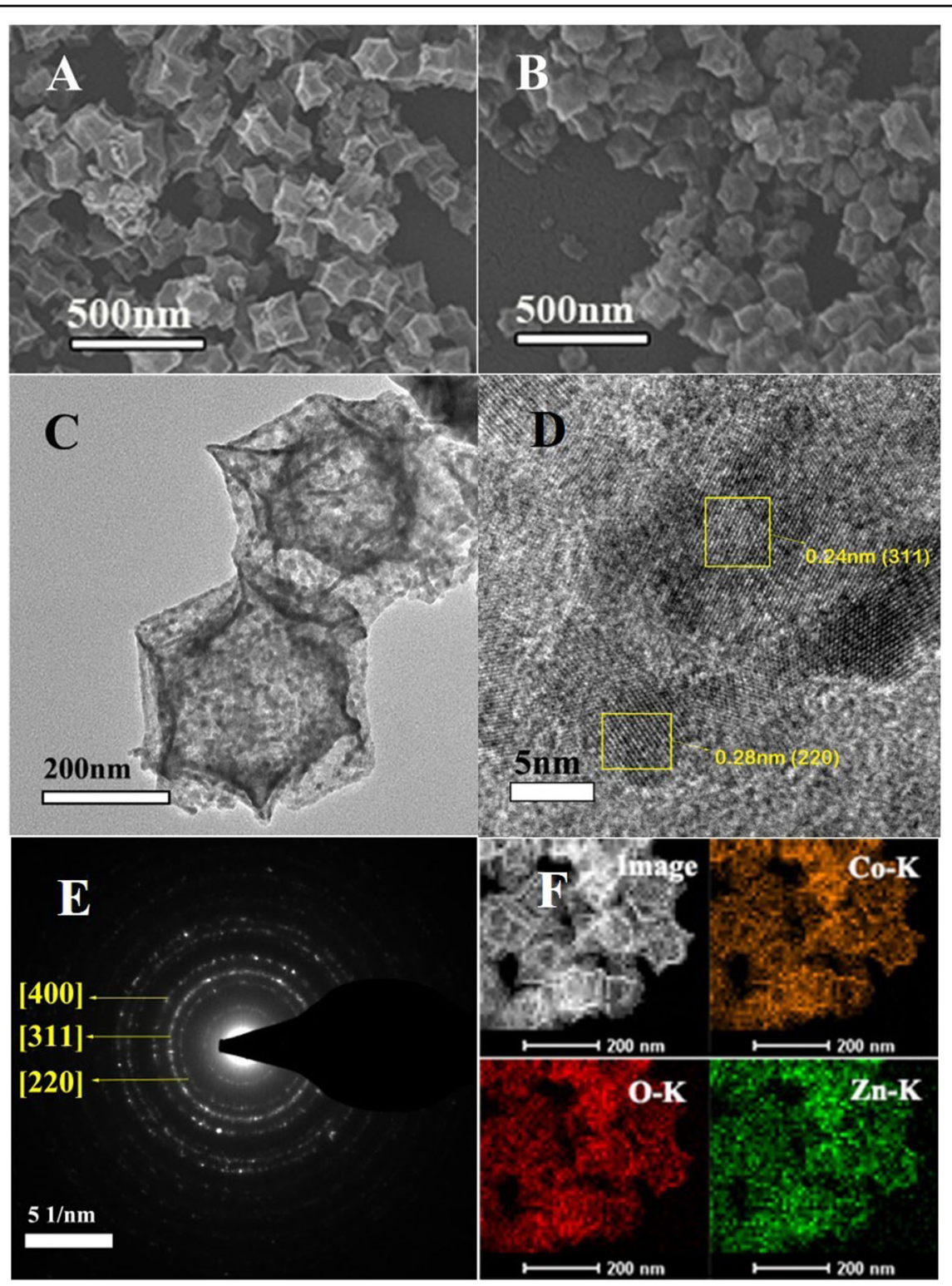

Fig. 1 Morphology characterizations of $\mathbf{Z n}$-doped $\mathrm{Co}_{3} \mathrm{O}_{\mathbf{4}}$. SEM images of $\mathbf{A} \mathrm{CO}_{3} \mathrm{O}_{4}$ dodecahedra and $\mathbf{B}$ Zn-doped $\mathrm{Co}_{3} \mathrm{O}_{4}-2, \mathbf{C}$ TEM image of $Z \mathrm{n}$ doped $\mathrm{CO}_{3} \mathrm{O}_{4}-2$, D HRTEM image of $\mathrm{Zn}$-doped $\mathrm{CO}_{3} \mathrm{O}_{4}-2$, E SAED pattern of $\mathrm{Zn}$-doped $\mathrm{CO}_{3} \mathrm{O}_{4}-2$, and $\mathbf{F}$ STEM image and the corresponding EDX elemental mapping images of $\mathrm{Co}, \mathrm{Zn}$, and $\mathrm{O}$ for $\mathrm{Zn}$-doped $\mathrm{CO}_{3} \mathrm{O}_{4}$ hollow dodecahedra.

$\mathrm{Co}_{3} \mathrm{O}_{4}$, which introduces a large number of oxygen vacancies that facilitate $\mathrm{OH}^{-}$adsorption in a $\mathrm{KOH}$ solution during the OER process ${ }^{21,22}$. However, a decrease in the oxygen vacancy concentration is detected for the $\mathrm{Zn}$ doped $\mathrm{Co}_{3} \mathrm{O}_{4}-1$ sample. We assume the reason for this is that when an excessive amount of the $\mathrm{Zn}\left(\mathrm{NO}_{3}\right)_{2} \cdot 6 \mathrm{H}_{2} \mathrm{O}$ precursor is added, the probability for the formation of $\mathrm{ZnCo}_{2} \mathrm{O}_{4}$ may increase; the XRD pattern of which is quite similar to that of $\mathrm{Co}_{3} \mathrm{O}_{4}{ }^{35,36}$. As a result, the proportion of $\mathrm{Co}^{2+}$ can be decreased, and the corresponding ratio of $\mathrm{Co}^{3+}$ may be increased, which can lead to a decrease in the number of oxygen vacancies.
$\mathrm{N}_{2}$ sorption isotherms are conducted to quantify the porosity and specific surface area of catalysts, and the pore size distribution curve can be obtained by the Barrett-Joyner-Halenda (BJH) method (Fig. S4). $\mathrm{Co}_{3} \mathrm{O}_{4}$ hollow dodecahedra present a mesoporous structure with a narrow distribution centered at $5 \mathrm{~nm}$ (the inset of Fig. S4A). It is notable that with an increasing doping amount of $\mathrm{Zn}$, enlarged mesopores that are above $5 \mathrm{~nm}$ are detected (the insets of Fig. S4). Commercial $\mathrm{Co}_{3} \mathrm{O}_{4}$ particles are also tested for comparison (Fig. S4E). Through the Brunauer-Emmett-Teller (BET) analysis, the surface areas of all catalysts are in the sequence of 

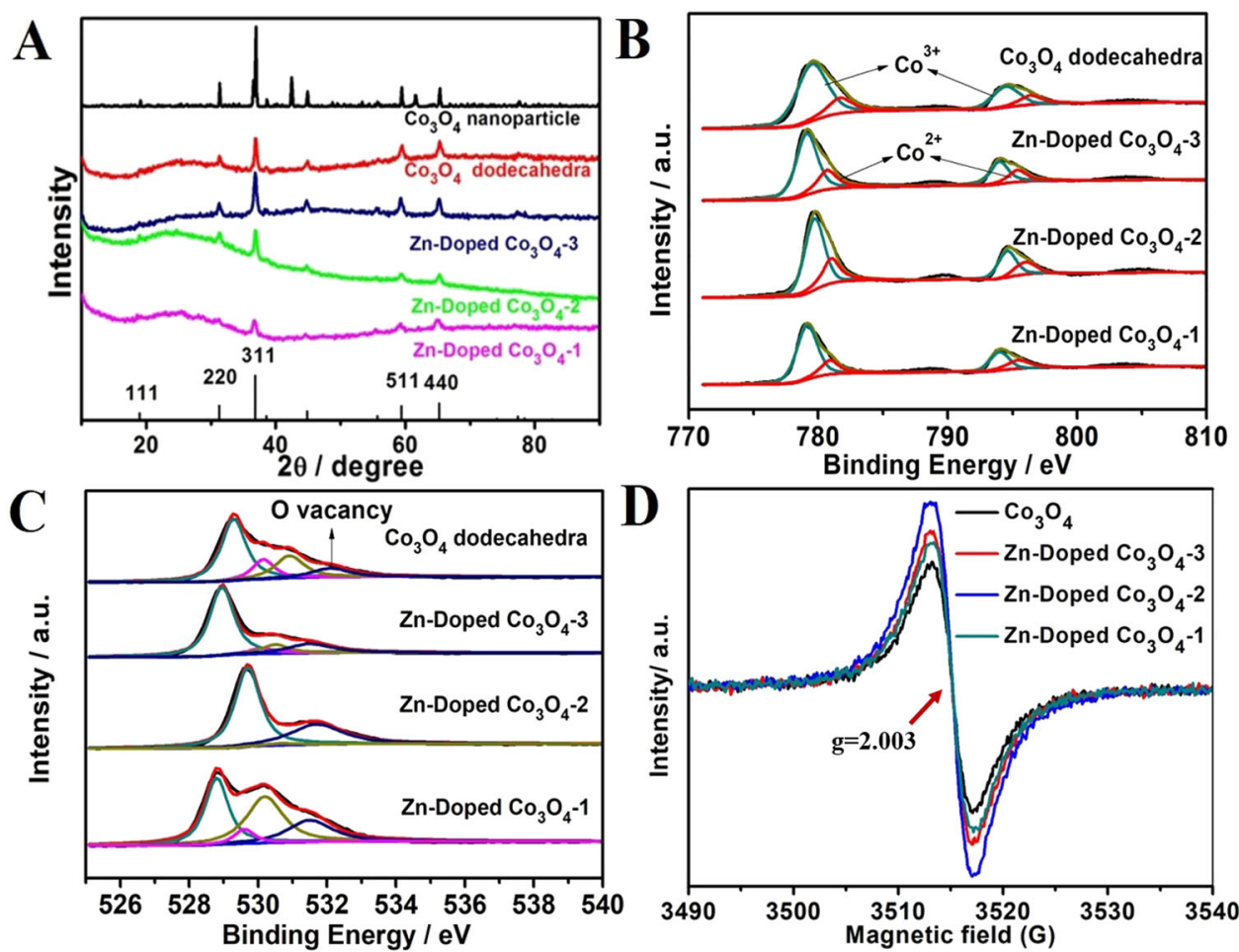

Fig. 2 Structural characterizations of $\mathbf{Z n}$-doped $\mathbf{C o}_{3} \mathbf{O}_{\mathbf{4}}$. A XRD patterns of all samples, $\mathbf{B}$ XPS spectra in the Co $2 p$ region for all samples, $\mathbf{C}$ XPS spectra in the $\mathrm{O} 1 \mathrm{~s}$ region for all samples, and $\mathbf{D}$ EPR spectra of all samples.

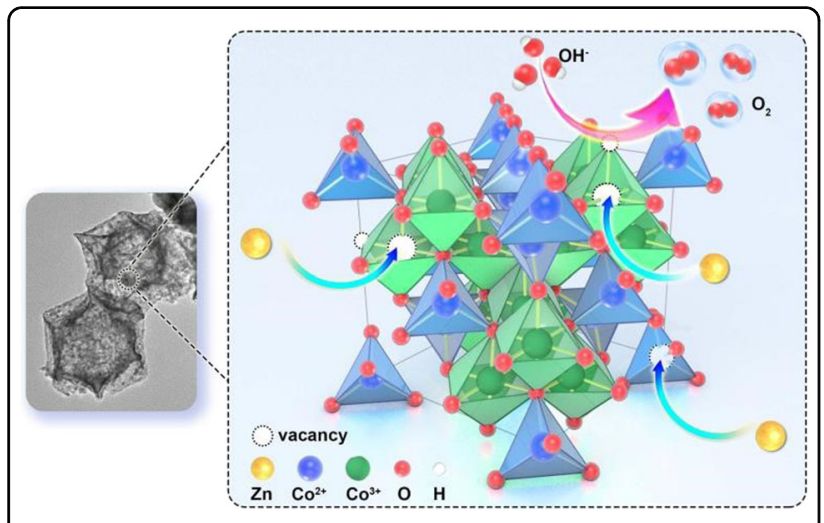

Fig. 3 Schematic illustration of $\mathrm{Zn}$-doped $\mathrm{Co}_{3} \mathrm{O}_{4}$. Schematic showing the process for the formation of oxygen vacancies.

Zn-doped $\mathrm{Co}_{3} \mathrm{O}_{4}-1\left(179 \mathrm{~m}^{2} / \mathrm{g}\right)>\mathrm{Zn}$-doped $\mathrm{Co}_{3} \mathrm{O}_{4}-2(120$ $\left.\mathrm{m}^{2} / \mathrm{g}\right)>\mathrm{Zn}$-doped $\mathrm{Co}_{3} \mathrm{O}_{4}-3\left(100.1 \mathrm{~m}^{2} / \mathrm{g}\right) \approx \mathrm{Co}_{3} \mathrm{O}_{4}$ hollow dodecahedra $\left(100 \mathrm{~m}^{2} / \mathrm{g}\right)>\mathrm{Co}_{3} \mathrm{O}_{4}$ nanoparticles $\left(54 \mathrm{~m}^{2} / \mathrm{g}\right)$. This phenomenon can be attributed to the substitution of $\mathrm{Zn}$ ions for Co ions, which results in the decreased crystallinity of cobalt oxide films, as confirmed by the XRD shown in Fig. 2A. As the degree of crystallization decreases, an increase in defects, such as pores, voids, and intragrain boundaries, will emerge, thus causing an increase in the surface area.
The OER performances of all the catalysts were compared in $1 \mathrm{M} \mathrm{KOH}$ solution at a scan rate of $5 \mathrm{mV} \mathrm{s}^{-1}$ (Fig. 4A). $\mathrm{Zn}$-doped $\mathrm{Co}_{3} \mathrm{O}_{4}-2$ shows an overpotential as low as $353 \mathrm{mV}$ at a current density of $10 \mathrm{~mA} \mathrm{~cm}^{-2}$, which compares favorably to the $\mathrm{Co}_{3} \mathrm{O}_{4}$ dodecahedra $\left(\eta_{10 \mathrm{mAcm}-2}=379 \mathrm{mV}\right), \mathrm{Co}_{3} \mathrm{O}_{4}$ particles $\left(\eta_{10 \mathrm{mAcm}-2}=430 \mathrm{mV}\right)$ and most of the $\mathrm{Co}_{3} \mathrm{O}_{4}$ catalysts in alkaline media (as presented in Table S3). The enhanced activity of $\mathrm{Zn}$-doped $\mathrm{Co}_{3} \mathrm{O}_{4}-2$ is derived from its abundant oxygen vacancies. The electrochemical surface areas (ECSAs) of the catalysts can be reflected by the double-layer capacitance $\left(\mathrm{C}_{\mathrm{DL}}\right)$. As shown in Fig. S5, the double-layer charging current (j) equals the scan rate $(v)$, and $C_{D L}$ is calculated according to the equation $j=v C_{D L}{ }^{37,38}$. As shown in Fig. $4 B$, the catalytic activities for the different catalysts are found to correlate well with the variations in $\mathrm{C}_{\mathrm{DL}}$ ( $\mathrm{Zn}$-doped $\mathrm{Co}_{3} \mathrm{O}_{4}-2>\mathrm{Zn}$-doped $\mathrm{Co}_{3} \mathrm{O}_{4}-3>$ $\mathrm{Co}_{3} \mathrm{O}_{4}$ dodecahedra $>\mathrm{Zn}$-doped $\mathrm{Co}_{3} \mathrm{O}_{4}-1>\mathrm{Co}_{3} \mathrm{O}_{4}$ nanoparticle). The reason for this result can be ascribed to the enlarged ECSA, which increases accessibility and promotes the reaction ${ }^{39}$. It is worth noting that although $\mathrm{Zn}$-doped $\mathrm{Co}_{3} \mathrm{O}_{4}-1$ possesses the largest surface area through BET $\left(179 \mathrm{~m}^{2} / \mathrm{g}\right)$, its ECSA is smaller than that of other $\mathrm{Zn}$-doped $\mathrm{Co}_{3} \mathrm{O}_{4}$ samples, probably due to the excessive content of doped $\mathrm{Zn}$. Zn is less catalytically active for the OER; therefore, an excessive content of doped $\mathrm{Zn}$ results in a decrease in the number of active sites, thereby leading to poor catalytic 

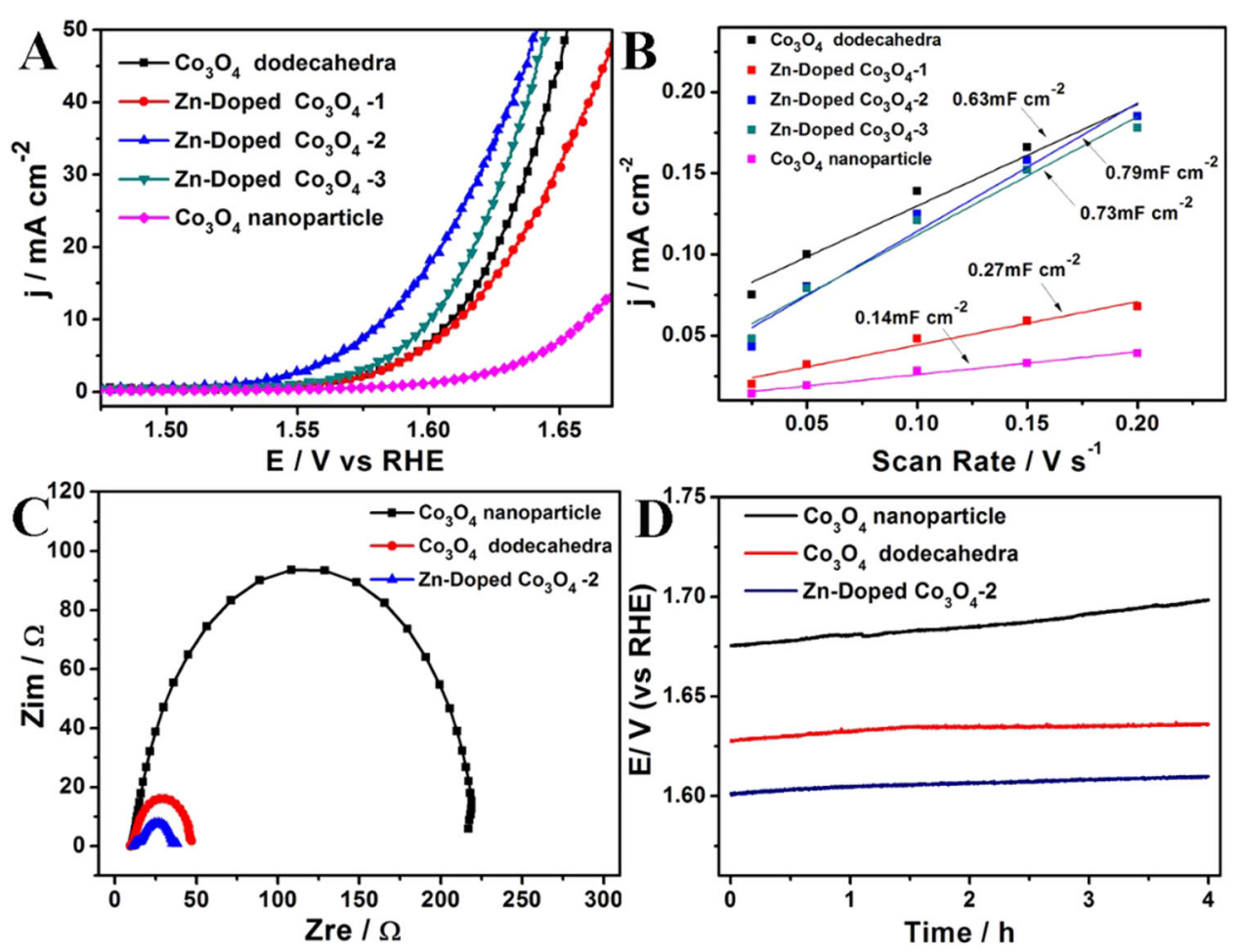

Fig. 4 Electrocatalytic OER performance of $\mathbf{Z n}$-doped $\mathrm{Co}_{3} \mathrm{O}_{4}$. A LSV curves of all catalysts in $1 \mathrm{M} \mathrm{KOH}$ at a scan rate of $5 \mathrm{mVs}^{-1}$; $\mathbf{B}$ linear plot of the capacitive current density vs. scan rate for all catalysts, and the double-layer capacitance $\left(C_{D L}\right)$ is determined by the slope of the fitting line; $\mathbf{C} A C$ impedance spectra of the (a) $\mathrm{CO}_{3} \mathrm{O}_{4}$ nanoparticles, (b) $\mathrm{CO}_{3} \mathrm{O}_{4}$ dodecahedra, and (c) $\mathrm{Zn}$-doped $\mathrm{Co}_{3} \mathrm{O}_{4}-2$ at $1.6 \mathrm{~V}$ (vs RHE); and D chronopotentiometry measurements of the (a) $\mathrm{CO}_{3} \mathrm{O}_{4}$ nanoparticles, (b) $\mathrm{CO}_{3} \mathrm{O}_{4}$ dodecahedra, and (c) $\mathrm{Zn}$-doped $\mathrm{CO}_{3} \mathrm{O}_{4}-2$ at a current density of $10 \mathrm{mAcm}^{-2}$ for $4 \mathrm{~h}$ in $1 \mathrm{M} \mathrm{KOH}$.

activity. AC impedance spectra are used to probe the charge transfer resistance. It is clear that at $1.6 \mathrm{~V}$, the charge transfer resistances of $\mathrm{Zn}$-doped $\mathrm{Co}_{3} \mathrm{O}_{4}-2$ and $\mathrm{Co}_{3} \mathrm{O}_{4}$ dodecahedra are much smaller than that of the $\mathrm{Co}_{3} \mathrm{O}_{4}$ nanoparticle (Fig. $4 \mathrm{C}$ ), which demonstrates the facilitation of the OER reaction kinetics and leads to superior electrochemical performance for the OER. Finally, the stability of catalysts is evaluated by using controlled-current electrolysis. The electrodes were held at a constant current density of $10 \mathrm{~mA} \mathrm{~cm}{ }^{-2}$, while the operating potential was measured as a function of time. As shown in Fig. 4D, during the 4-h electrolysis process, the decay rates for the $\mathrm{Co}_{3} \mathrm{O}_{4}$ dodecahedra and $\mathrm{Zn}$-doped $\mathrm{Co}_{3} \mathrm{O}_{4}-2$ are 2.25 and $2 \mathrm{mVh}^{-1}$, respectively, much smaller than the $6 \mathrm{mVh}^{-1}$ for commercial $\mathrm{Co}_{3} \mathrm{O}_{4}$ particles. These results show that the hollow dodecahedral structure can improve the catalytic stability of $\mathrm{Co}_{3} \mathrm{O}_{4}$ during the electrolysis process.

\section{Conclusion}

We prepared $\mathrm{Zn}$-doped $\mathrm{Co}_{3} \mathrm{O}_{4}$ hollow dodecahedra with different $\mathrm{Co} / \mathrm{Zn}$ ratios by the thermal treatment of an MOF, and the resulting products exhibited enhanced electrochemical activity for the OER with a small overpotential of $353 \mathrm{mV}$ at a current density of $10 \mathrm{~mA} \mathrm{~cm}^{-2}$.
Moreover, an improved OER stability was observed, with a decay rate of $2 \mathrm{mV} \mathrm{h}^{-1}$ for the $\mathrm{Zn}$-doped $\mathrm{Co}_{3} \mathrm{O}_{4}$ hollow dodecahedra. We believe that the unique architecture (enlarged surface area, porosity) of $\mathrm{Zn}$-doped $\mathrm{Co}_{3} \mathrm{O}_{4}$ hollow dodecahedra and the composition change caused by the doping of $\mathrm{Zn}$ (increased oxygen defects) are responsible for its superior electrochemical performance. These results emphasize the importance of engineering both the external morphology and internal composition of OER catalysts, where the good interplay between the two leads to greatly boosted electrocatalytic behavior.

\section{Acknowledgements}

This work is supported by the National Key R\&D Program of China (No 2018YFB1502400), the Strategic Priority Research Program of CAS

(XDA09030104), the Jilin Province Science and Technology Development Program (20160622037JC), the Hundred Talents Program of the Chinese Academy of Sciences and the Recruitment Program of Foreign Experts (WQ20122200077). W.X. thanks the Gusu talent program for their financial support.

\section{Author details}

${ }^{1}$ State Key Laboratory of Electroanalytical Chemistry, Jilin Province Key Laboratory of Low Carbon Chemical Power, Changchun Institute of Applied Chemistry Chinese Academy of Sciences, 5625 Renmin Street, Changchun 130022, P.R. China. ${ }^{2}$ College of Materials Science and Engineering, Qingdao University of Science and Technology, Qingdao 266042, P.R. China. ${ }^{3}$ University of Science and Technology of China, Hefei 230026, P.R. China 


\section{Conflict of interest}

The authors declare that they have no conflict of interest.

\section{Publisher's note}

Springer Nature remains neutral with regard to jurisdictional claims in published maps and institutional affiliations.

Supplementary information is available for this paper at https://doi.org/ 10.1038/s41427-020-00255-y.

Received: 25 February 2020 Revised: 10 May 2020 Accepted: 18 May 2020. Published online: 13 November 2020

\section{References}

1. Joya, K. S., Joya, Y. F., Ocakoglu, K. \& van de Krol, R. Water-Splitting catalysis and solar fuel devices: artificial leaves on the move. Angew. Chem. Int. Ed. 52, 10426-10437 (2013)

2. Hong, W. T. et al. Toward the rational design of non-precious transition metal oxides for oxygen electrocatalysis. Energy Environ. Sci. 8, 1404-1427 (2015).

3. Suntivich, J., May, K. J., Gasteiger, H. A., Goodenough, J. B. \& Shao-Horn, Y. A Perovskite oxide optimized for oxygen evolution catalysis from molecular orbital principles. Science 334, 1383-1385 (2011).

4. Lee, Y., Suntivich, J., May, K. J., Perry, E. E. \& Shao-Horn, Y. Synthesis and activities of rutile $\mathrm{IO}_{2}$ and $\mathrm{RuO}_{2}$ nanoparticles for oxygen evolution in acid and alkaline solutions. J. Phys. Chem. Lett. 3, 399-404 (2012).

5. Augustyn, V., Therese, S., Turner, T. C. \& Manthiram, A. Nickel-rich layered LiNi ${ }_{x} \mathrm{M}_{\mathrm{x}} \mathrm{O}_{2}(\mathrm{M}=\mathrm{Mn}, \mathrm{Fe}$, and $\mathrm{Co})$ electrocatalysts with high oxygen evolution reaction activity. J. Mater. Chem. A 3, 16604-16612 (2015).

6. Lambert, T. N. et al. Electrodeposited $\mathrm{Ni}_{x} \mathrm{CO}_{3-\mathrm{x}} \mathrm{O}_{4}$ nanostructured films as bifunctional oxygen electrocatalysts. Chem. Commun. 51, 9511-9514 (2015).

7. Wang, J. H. et al. Recent progress in cobalt-based heterogeneous catalysts for electrochemical water splitting. Adv. Mater. 28, 215-230 (2016).

8. Han, L., Dong, S. J. \& Wang, E. K. Transition-metal (Co, Ni, and Fe)-based electrocatalysts for the water oxidation reaction. Adv. Mater. 28, 9266-9291 (2016).

9. Bae, S. H. et al. Seamlessly conductive $3 \mathrm{D}$ nanoarchitecture of core-shell ni-co nanowire network for highly efficient oxygen evolution. Adv. Energy Mater. 7 1601492 (2017).

10. Zhao, H., Zhu, Y.-P. \& Yuan, Z.-Y. Three-dimensional electrocatalysts for sustainable water splitting reactions. Eur. J. Inorg. Chem. 2016, 1916-1923 (2016).

11. Liu, G., Gao, X. S., Wang, K. F., He, D. Y. \& Li, J. P. Mesoporous nickel-iron binary oxide nanorods for efficient electrocatalytic water oxidation. Nano Res. 10, 2096-2105 (2017).

12. Ataee-Esfahani, $\boldsymbol{H}$. et al. Mesoporous metallic cells: design of uniformly sized hollow mesoporous Pt-Ru particles with tunable shell thicknesses. Small $\mathbf{9}$ 1047-1051 (2013).

13. Wang, B., Chen, J. S., Wu, H. B., Wang, Z. \& Lou, X. W. Quasiemulsion-templated formation of $\mathrm{a}-\mathrm{Fe}_{2} \mathrm{O}_{3}$ hollow spheres with enhanced lithium storage properties. J. Am. Chem. Soc. 133, 17146-17148 (2011).

14. Caruso, F., Caruso, R. A. \& Mohwald, H. Nanoengineering of inorganic and hybrid hollow spheres by colloidal templating. Science 282, 1111-1114 (1998).

15. Wu, R. et al. Zeolitic imidazolate framework 67-derived high symmetric porous $\mathrm{CO}_{3} \mathrm{O}_{4}$ hollow dodecahedra with highly enhanced lithium storage capability. Small 10, 1932-1938 (2014).

16. Cho, W., Lee, Y. H., Lee, H. J. \& Oh, M. Multi ball-in-ball hybrid metal oxides. Adv. Mater. 23, 1720-1723 (2011).

17. Liu, X. et al. Chemlnform Abstract: Hierarchical $\mathrm{Zn}_{x} \mathrm{CO}_{3-x} \mathrm{O}_{4}$ nanoarrays with high activity for electrocatalytic oxygen evolution. Cheminform 45 (2014).
18. Liu, Z. Q., Cheng, H., Li, N., Ma, T. Y. \& Su, Y. Z. $\mathrm{ZnCO}_{2} \mathrm{O}_{4}$ quantum dots anchored on nitrogen-doped carbon nanotubes as reversible oxygen reduction/evolution electrocatalysts. Adv. Mater. 28, 3777-3784 (2016).

19. Menezes, P. W. et al. Cobalt-manganese-based spinels as multifunctional materials that unify catalytic water oxidation and oxygen reduction reactions. ChemSusChem 8, 164-171 (2015).

20. Zhu, C. et al. Nickel cobalt oxide hollow nanosponges as advanced electrocatalysts for the oxygen evolution reaction. Chem. Commun. 51, 7851-7854 (2015).

21. Li, Y., Tan, B. \& Wu, Y. Mesoporous $\mathrm{CO}_{3} \mathrm{O}_{4}$ nanowire arrays for lithium ion batteries with high capacity and rate capability. Nano Lett. 8, 265-270 (2008).

22. $\mathrm{Xu}$, L. et al. Plasma-engraved $\mathrm{CO}_{3} \mathrm{O}_{4}$ nanosheets with oxygen vacancies and high surface area for the oxygen evolution reaction. Angew. Chem. Int. Ed. $\mathbf{5 5}$ 5277-5281 (2016)

23. Chi, B., Li, J., Yang, X., Lin, H. \& Wang, N. Electrophoretic deposition of ZnCoO spinel and its electrocatalytic properties for oxygen evolution reaction. Electrochim. Acta 50, 2059-2064 (2005).

24. Shi, N., Cheng, W., Zhou, H., Fan, T. \& Niederberger, M. Facile synthesis of monodisperse $\mathrm{CO}_{3} \mathrm{O}_{4}$ quantum dots with efficient oxygen evolution activity. Chem. Commun. 51, 1338-1340 (2015)

25. Baird, T. et al. Characterisation of cobalt-zinc hydroxycarbonates and theirproducts of decomposition. J. Mater. Chem. 7, 319-330 (1997).

26. Ma, T. Y, Dai, S, Jaroniec, M. \& Qiao, S. Z. Metal-organic framework derived hybrid $\mathrm{CO}_{3} \mathrm{O}_{4}$-carbon porous nanowire arrays as reversible oxygen evolution electrodes. J. Am. Chem. Soc. 136, 13925-13931 (2014).

27. Tüysüz, H., Liu, Y., Weidenthaler, C. \& Schüth, F. Pseudomorphic transformation of highly ordered mesoporous $\mathrm{CO}_{3} \mathrm{O}_{4}$ to $\mathrm{CoO}$ via reduction with glycerol. J. Am. Chem. Soc. 130, 14108-14110 (2008).

28. Liao, L. et al. Efficient solar water-splitting using a nanocrystalline CoO photocatalyst.Nat. Nanotechnol. 9, 69-73 (2014).

29. Zhang, J., Yin, R., Shao, Q., Zhu, T. \& Huang, X. Oxygen vacancies in amorphous InOx nanoribbons enhance $\mathrm{CO}_{2}$ adsorption and activation for $\mathrm{CO}_{2}$ electroreduction. Angew. Chem. Int Ed. Engl. 58, 5609-5613 (2019).

30. Kim, M. et al. Oxygen-vacancy-introduced $\mathrm{BaSnO}_{3}$-delta photoanodes with tunable band structures for efficient solar-driven water splitting. Adv. Mater. 31, 1903316 (2019)

31. Lei, F. et al. Oxygen vacancies confined in ultrathin indium oxide porous sheets for promoted visible-light water splitting. J. Am. Chem. Soc. 136 6826-6829 (2014)

32. Liang, G. et al. A long cycle-life high-voltage spinel lithium-ion battery electrode achieved by site-selective doping. Angew Chem. Int Ed. 59, 10594-10602 (2020).

33. Zhuang, L. et al. Ultrathin iron-cobalt oxide nanosheets with abundant oxygen vacancies for the oxygen evolution reaction. Adv. Mater. 29, 1606793 (2017).

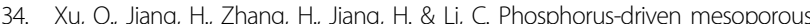
$\mathrm{CO}_{3} \mathrm{O}_{4}$ nanosheets with tunable oxygen vacancies for the enhanced oxygen evolution reaction. Electrochim. Acta 259, 962-967 (2018).

35. Wang, Q., Zhu, L., Sun, L., Liu, Y. \& Jiao, L. Facile synthesis of hierarchical porous $\mathrm{ZnCO}_{2} \mathrm{O}_{4}$ microspheres for high-performance supercapacitors. J. Mater. Chem A 3, 982-985 (2015).

36. Wang, S., Ding, Z. \& Wang, X. A stable $\mathrm{ZnCO}_{2} \mathrm{O}_{4}$ cocatalyst for photocatalytic $\mathrm{CO}_{2}$ reduction. Chem. Commun. 51, 1517-1519 (2015).

37. McCrory, C. C. L., Jung, S., Peters, J. C. \& Jaramillo, T. F. Benchmarking heterogeneous electrocatalysts for the oxygen evolution reaction. J. Am. Chem Soc. 135, 16977-16987 (2013).

38. Liu, W., Zhu, M., Liu, J., Li, X. \& Liu, J. Flexible asymmetric supercapacitor with high energy density based on optimized $\mathrm{MnO}_{2}$ cathode and $\mathrm{Fe}_{2} \mathrm{O}_{3}$ anode. Chin. Chem. Lett. 30, 750-756 (2019).

39. Liu, $\mathrm{X}$. et al. Hierarchical $\mathrm{Zn}_{x} \mathrm{CO}_{3-x} \mathrm{O}_{4}$ nanoarrays with high activity for electrocatalytic oxygen evolution. Chem. Mater. 26, 1889-1895 (2014). 